\title{
Recurrent Pneumonia in Children Admitted to Assiut University Children Hospital. Magnitude of the Problem and Possible Risk Factors
}

\section{Corresponding author:}

George S. Shaker

Email:drgeorge_sobhy7@yahoo.com Tel: 01203222186
Medical Research Journal 2019; Volume 4, Number 1, 13-24 DOI: 10.5603/MRJ.a2019.0001 Copyright (C 2019 Via Medica ISSN 2451-2591

\begin{abstract}
Background: Incidence data indicate that recurrent pneumonia occurs in $7.7-9 \%$ of all children with community acquired pneumonia. We aim by this study to assess the prevalence of recurrent pneumonia among the admissions with diagnosis of pneumonia in Assiut university children hospital for one year and to try to define the possible related risk factors. Patients and methods: This is a prospective hospital based study in Assiut University Children's Hospital. Children younger than 16 years admitted with a hospital diagnosis of pneumonia to Assiut University Children's Hospital for one year from 1 February 2017 to 31 January 2018 were included.

Results: Approximately 1 in 12 children with pneumonia in our locality have recurrent pneumonia with percentage of $12.61 \%$. Cardiac diseases especially congenital heart diseases was the cause among $25.45 \%$ of the cases, immunodeficiency diseases represented $20.9 \%$ of the cases , while bronchial asthma was the cause of recurrent pneumonia among $16.36 \%$ of the cases. As regard to risk factors in studied group, prematurity was detected among $7.27 \%$ of the cases while more than $50 \%$ were formula fed and more than $60 \%$ exposed to pollution. Father smoking was detected among $36.36 \%$ of cases. Patients aged $>6$ years showed significantly higher frequency in risk factors as obesity, indoor and outdoor pollution and use of steroids in comparison to other age groups. However, patients aged 0-3 years exhibited significantly higher $\%$ frequency of having heart disease, oro-motor in coordination /swallowing dysfunction, gastro esophageal reflux and under nutrition as risk factors for recurrent pneumonia in comparison to other age groups. Conclusions: The most frequent underlying cause for recurrent pneumonia in Assiut University Children's Hospital which presents the largest referral pediatric hospital in Upper Egypt for one year according to our study was cardiac diseases; the second most frequent cause was immunodeficiency diseases, followed by bronchial asthma. Risk factors for recurrent pneumonia include socio-economic status of studied cases, prematurity, exposure to passive smoking and in or outdoor pollution, obesity, under nutrition, lack of breast feeding, gastro esophageal reflux and steroids usage.

Key words: Recurrent pneumonia, community acquired pneumonia congenital heart disease, gastro esophageal reflux disease, immunodeficiency diseases, bronchial asthma, socio-economic status, chronic lung diseases, pulmonary tuberculosis , aspiration syndrome, anatomical congenital respiratory anomalies, cystic fibrosis.
\end{abstract}

Med Res J 2019; 4 (1): 13-24

\section{Introduction}

Pneumonia is the top infectious killer of children under 5 years worldwide, resulting in 935,000 deaths each year. According to the "Global Action Plan for Prevention and Control of Pneumonia", around 20\% of the child deaths that occurred globally in 2007 were caused by pneumonia, and more than $90 \%$ of these deaths were in developing countries [3]. In Egypt, it was estimated that $10 \%$ of children deaths below the age of 5 years is likely caused by pneumonia and other acute respiratory infections [4]. Egypt has around 2 million cases of children with pneumonia every year [5], and 42,000 Egyptian children under 5 die annually [6]. Ap- 
proximately $6 \%$ of infants experience at least one episode of pneumonia during the first two years of life [7]. Recurrent pneumonia (RP) is defined as at least two episodes of pneumonia in one year or three episodes ever, with intercritical radiographic clearing of densities [8]. Incidence data indicate that RP occurs in 7.7-9\% of all children with community acquired pneumonia (CAP) [1, 2].As a result, $\mathrm{RP}$ represents a frequent presenting manifestation in the general pediatric practice and is a very common reason for referral to pediatric chest physicians [1]

The challenge for the physician approaching RP is to discriminate between children with self-limiting or minor problems, that do not require a diagnostic work-up, and those with an underlying disease, for whom further investigation is mandatory. Therefore, determining which child should be investigated relies on clinical judgment, that should take into account the patient's history, the clinical course of the episode, and any symptoms and/or signs indicating the presence of an underlying disease [9].Most of the children hospitalized during the first episode of pneumonia had a known predisposing condition for pneumonia recurrence including neuromotor disorders with feeding problems, gastro-esophageal reflux ,congenital heart disease, asthma, airway malacia and vascular malformations [10].

The aim of the study is to assess the prevalence of recurrent pneumonia among the admissions with diagnosis of pneumonia in Assiut university children hospital for one year and to try to define the possible related risk factors.

\section{Patient and methods}

This is a prospective hospital based study in Assiut University Children's Hospital. Children younger than 16 years admitted with a hospital diagnosis of pneumonia to Assiut University Children's Hospital for one year from 1 February 2017 to 31 January 2018 were included.

All admissions to Assiut University Children Hospital were recorded over one year. Cases of pneumonia were identified and examined for criteria of recurrent pneumonia either on prospective bases.

Studied cases were subjected to the following:

\section{History}

Including age, sex, residence, neonatal history, socio-economic status for health research in Egypt (2012), duration of symptoms and treatment given, history suggestive of immunodeficiency (e.g. persistent diarrhea, cutaneous infections as boils, abscesses etc.). History of recurrent upper respiratory tract infections (defined as more than six serious URI with fever, cough, sore throat and running nose per year and history of pervious hospitalization, history of contact with tuberculosis patient, immunization status, developmental milestones and history of risk factors as prematurity, co morbid conditions as (heart diseases, GERD, oromotor or swallowing dysfunction) parental smokingand environmental pollution.

\section{Clinical Examination}

Complete physical examination including vital signs, anthropometric measurement and calculating body mass index (BMI) which equal weight divided by square of the body height in units of $\mathrm{kg} / \mathrm{m} 2$ for children more than 2 years old, calculating weight for height, weight for age and height for age percentiles for children less than 2 years old for assessment of nutritional status. Also presence and degree (if present) of respiratory distress, clubbing and full chest and cardiac examination were assessed.

\section{Investigations}

All cases of recurrent pneumonia were subjected to the following investigations:

1. Pulse oxmeter assessment.

2. Chest X-ray.

3. Complete blood count with differential count.

4. C- reactive protein assay.

5. Mantous test (Tuberculin sensitivity test).

6. Echocardiography.

Moreover, some cases with recurrent pneumonia well be subjected

(According to every case individually based on history and clinical examination) to:

1. Computerized tomography of the chest in cases suspected of chronic lung diseases, anatomical congenital respiratory anomalies and suspected F.B inhalation.

2. Abdominal ultrasound and barium or gastro-graffin swallow with x-ray study in cases suspected gastro-esophageal reflux and recurrent aspiration.

3. Laryngoscopy or flexible fiber-optic bronchscopy in cases of recurrence of pneumonia on the same side, suspected laryngo or bronchomalacia and suspected F.B inhalation

4. Immunoglobulin quantitative assay, number of $T$ and B lymphocytes and flow cytometric quantitative determination of leukocyte oxidative burst for children suspected to have immunodeficiency.

5. Cystic fibrosis DNA analysis for cases clinically suspicious having Cystic fibrosis.

6. Enzyme linked immunosorbant assay (ELISA) for human immunodeficiency virus (HIV) infection for suspected cases.

\section{Inclusion criteria}

Infants and children below 16 years old diagnosed on clinical and radiological grounds as recurrent 
Table 1. Socio-economic status according to EL Sherbini Modified Score (2012)

Name of head of family: $\quad$ Address:

Definition of the family: It includes nuclear cc joint family Married couple with unmanied children or without children. Head of the family will be either husband/wife. Dependent father/mother/brother/sister does not become member of the family unless he/she is earning and one kitchen with pooled income is managed by him/her.

This scale includes 7 domains with a total score of 84 .

Sodoeconomic level: to be classified into very low, low, middle and high levels depending on the quartiles of the score calculated.

NB In case of death or retirement of husband or wife, record the education and occupation before death or retirement

$\begin{array}{lcc}\begin{array}{l}\text { Education and cultural domain } \\ \text { (for both husband \& wife) }\end{array} & & \\ \text { (score }-30 \text { ) } & & \\ \text { Highest level of education } & \text { Husband } & \text { Wife } \\ \text { Illiterate } & 0 & 0 \\ \text { Read \& write } & 2 & 2 \\ \text { Primary } & 4 & 4 \\ \text { Preparatory } & 6 & 6 \\ \text { Secondary (general \& technical of } & 8 & 8 \\ 3 \text { or 5 years) } & & \\ \text { Intermediate (2 years) institutes } & 10 & 10 \\ \text { University graduate } & 12 & 12 \\ \text { Postgraduate degree } & 14 & 14\end{array}$

Access to health information (1 each for the following items): Printed materials, e.g. books, posters, booklets, etc.; Audiovisual message on television \&/or radio

\section{Family domain}

(score -10)

Residence: Urban slum - 0; Rural -1; Urban - 2

Number of family members (parents, children \& all de-

pendents): $<5$ members $-2 ; \geq 5$ members -1

Number of earning family members: 1 member $-1 ; 2$ members

$-2 ; \geq 3$ members -3

Education of children (aged $\geq 5$ years, whether free or private education): All children going or ever gone to school/university $-3 ; \geq 50 \%$ going or ever gone to school/university $-2 ;<50 \%$ going or ever gone to

school/university - 1; None go/gone to school/university/not applicable - 0

\section{Economic domain}

(score - 5)

Income from all sources: In debt - 0; 1 Just meet routine expenses - 1; Meet routine expenses and emergencies - 2; Able to save/invest money -3

Family receives govemmental support: Yes -1 ; No -0

Family pays tax: Yes -1 ; No -0

\section{Occupation domain}

(for both husband \& wife)

(score -10

Occupation

Non-working/housewife

Unskilled manual worker

Skilled manual worker/farmer

Trades/business

Semi-professional/clerk

Professional

$\begin{array}{cc}\text { Husband } & \text { Wife } \\ 0 & 0 \\ 1 & 1 \\ 2 & 2 \\ 3 & 3 \\ 4 & 4 \\ 5 & 5\end{array}$

\section{Family possessions domain}

(score - 12: 1 each for the presence of items given below)

Refrigerator - Radio - Television - Washing machine

- Telephone/ mobile phone - Car - Agricultural land

- Non-agricuhural land for housing - Shop or animal shed

- Other house (beside the house in which the family is living)

- Animals/poultry - Computer/ Internet

\section{Home sanitation domain}

(score - 12)

Services (1 each for the presence of the following items): Pure water supply - Electricity - Natural gas - Sewerage system

- Municipal collection of solid wastes - Flush latrine - Air conditioning

Type of house: Owned, $\geq 4$ rooms -4 ; Owned, $<4$ rooms -3 ; Rented, $\geq 4$ rooms -2 ; Rented, $<4$ rooms -1 ; No place to reside -0

Crowing index: (number of family members divided by number of rooms): $\leq 1$ person per room $-1 ;>1$ person per room -0

\section{Health care domain}

(score - 5)

Usual source of health care: Private health facilities - 5; Health insurance -4 ; Free governmental health service -3 ; More than one of the above sources -2 Traditional healer/self care $-1$

Patients with obvious neurological diseases that lead to recurrent pneumonia also were excluded.

Patient clinically diagnosed as recurrent pneumonia, and those with non recurrent pneumonia will be subjected to $x$-ray examination for radiographic evidence of pneumonia .Only patient with radiographic evidence of pneumonia will be continued to be investigated.

\section{Results}

This study was done in Assiut University Children Hospital for one year from 1 February 2017 to 31 Janu- 
ary 2018 .All cases with pneumonia admitted to all units in the hospital have pneumonia were (872) case and (110) cases fulfilled the inclusion criteria of recurrent pneumonia with percentage of $12.61 \%$. Investigations were done:

- Mantous test was done for tuberculin sensitivity using 1T purified protein derivative (PPD) which was administered intradermally and reading was taken after 48-72 hours for all cases which included as recurrent pneumonia in the study. It was found that five cases had positive tuberculin testing. Gastric lavage and sputum study for acid fast bacilli were positive in two cases.

- Echocardiography was done to all cases included in the study and have recurrent pneumonia and twenty eight cases were found to have congenital heart disease.

- Gastro - esophageal reflux disease (GERD) was diagnosed in four children by clinical suspicion and confirmed by barium swallow.

- Abdominal ultrasound was done for all cases with clinically palpable organomegaly, cases with gastro esophageal reflux disease and for all cases with suspected to have immunodeficiency.

- Flexible fiberoptic bronchoscopy was performed for three cases with radiological evidence of recurrent atelectasis in same side showing chronic inflammatory process and for two cases diagnosed as bronchiectasis and two cases diagnosed as vascular ring.

- C.T scanning for chest examination was done for nine cases with atelectasis and lobar pneumonia and for all cases with chronic lung disease (Bronchiectasis, Interstitial lung fibrosis (IPF).

- Cystic fibrosis DNA analysis also shows only one case with Cystic fibrosis from clinically suspicious included patients.

Table 2. Demographic data of studied cases with recurrent pneumonia.

\begin{tabular}{lc}
\hline Item & Descriptive “n=110" \\
\hline 1. Gender: & \\
• Male & $72(65.45 \%)$ \\
• Female & $38(34.54 \%)$ \\
2. Age "years" & \\
Mean \pm SE & $3.91 \pm 0.40$ \\
(min-max) & $(0.2-16)$ \\
- 0-3 yrs. & $69(62.72 \%)$ \\
• > 3-6 yrs. & $15(13.63 \%)$ \\
• > 6 yrs. & $26(23.63 \%)$ \\
3. Residence: & \\
- Rural & $25(22.73 \%)$ \\
- Urban & $85(77.27 \%)$ \\
\hline
\end{tabular}

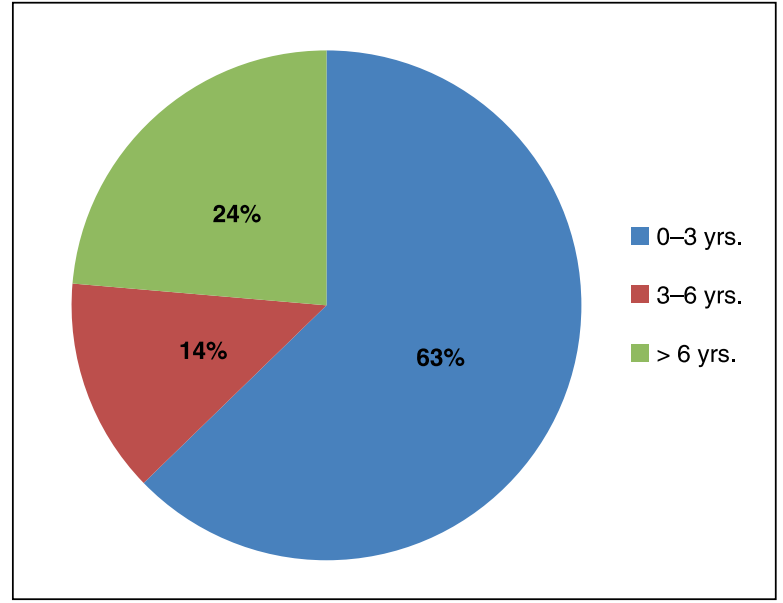

Figure 1. Distribution of age (years) among the studied patients.

- Enzyme linked immunosorbant assay (ELISA) for human immunodeficiency virus (HIV) infection to suspected five cases but all results were negative.

- Seven cases with recurrent pneumonia, the etiology of recurrence was unknown inspite of most of previous investigations were done to them.

Table 2 and figure 1 show demographic data of the studied cases. It was found that $(65.5 \%)$ of cases were males. The age ranged from $0.2-16$ years with mean age $3.91 \pm 0.40$ years. The majority of the included patients were belonged to age group $0-3$ years $(62.72 \%)$. About $(77.27 \%)$ of studied cases was from urban areas.

Table 3 shows socio-economic status of studied cases according to El Sherbini modified classification Score, (2012). According to maternal domain about half of mothers read \& write (54.54\%). About (77.2\%) of studied cases were from urban areas. Regarding occupation parents domain, there were (54.54\%) of the parents were skilled manual worker. About family possessions domains there were (59.09\%) had score 7. In economic domain the majority of cases (84.54\%) had met routine expenses \&emergencies. Also all cases had number of family members more than 5 members. Regarding crowding index there were about $(94.5 \%)$ of cases had more than one person/room. According to El Sherbini modified score (48.18\%) of the families belonged to middle class, while (43.64\%) were classified as low class.

Table 4 shows history in the included patients. The mean value of disease duration was $11.84 \pm 3.29$ days. There was history of cough among $(94.54 \%)$ of the patients, while $(56.36 \%)$ had history of fever and $(50.0 \%)$ had recurrent upper respiratory tract infection. About (22.72\%) cases had history of atopy/allergy and about (11.81\%) of cases had history of immuno-deficiency from first months of age. 
Table 5 shows descriptive data of investigations were done to the studied group including pulse oxime-

Table 3. Socio-economic status of studied cases according to ElSherbini modified Score (2012) in Egypt.

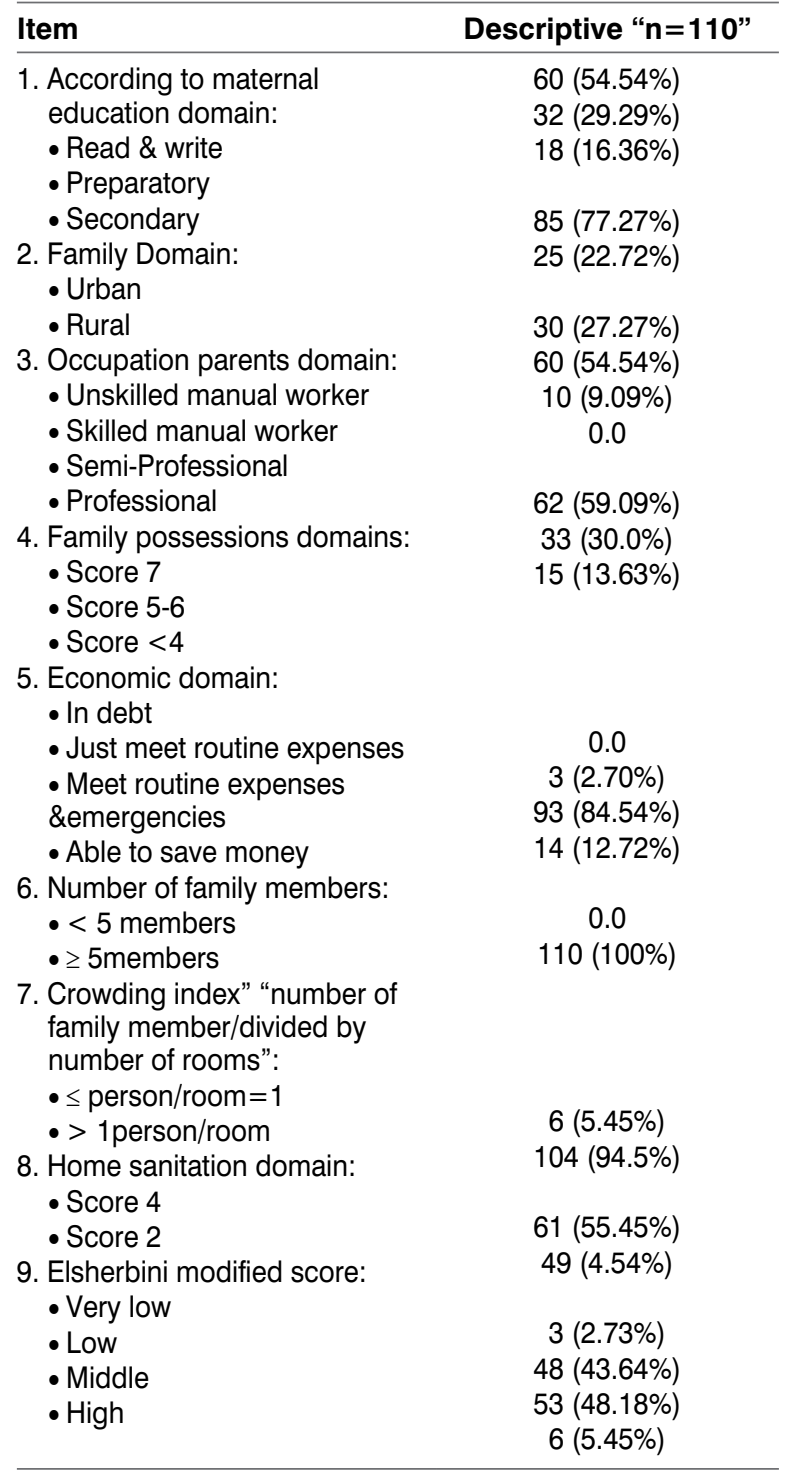

ter, C - reactive protein and complete blood count with differential count.

Table 6 and figure 2 show causes of recurrent pneumonia. The patients with cardiac disorders showed the highest \% frequency of cases of recurrent pneumonia $(25.45 \%)$, followed by $(20.9 \%)$ those with immuno-deficiency, while (16.36\%) of cases were due to bronchial asthma. However, (6.36\%) of the cases, the etiology was unknown.

Table 7 shows classification of cardiac causes of recurrent pneumonia. Patients with cyanotic heart diseases diagnosed as TGA (17.8\%) of the cases, while $(28.7 \%)$ of cardiac patients with a cyanotic heart diseases had ventricular septal defect.

Table 8 among 23 cases diagnosed with immunodeficiency, $(52.17 \%)$ were due to B-cell deficiency, while (26.08\%) were diagnosed as phagocytic cell defect.

Table 9 shows risk factors in study group. Prematurity was detected among $(7.27 \%)$ of the cases while more than $50 \%$ were formula fed and more than $60 \%$

Table 4. History analysis in the studied group.

\begin{tabular}{|c|c|}
\hline Item & Descriptive " $n=110 "$ \\
\hline 1. Duration of disease "days" & $11.84 \pm 3.29$ \\
\hline 2. Cough & 104 (94.54\%) \\
\hline 3. Fever & $62(56.36 \%)$ \\
\hline 4. Wheezing & $20(18.18 \%)$ \\
\hline $\begin{array}{l}\text { 5. Chronic rhino-sinusitis with } \\
\text { post-nasal drip }\end{array}$ & 00 \\
\hline $\begin{array}{l}\text { 6. Recurrent upper respiratory } \\
\text { tract infections }\end{array}$ & $55(50.0 \%)$ \\
\hline 7. Atopy/allergy & 25 (22.72\%) \\
\hline 8. Asthma & $19(17.27 \%)$ \\
\hline $\begin{array}{l}\text { 9. Unexplained death, severe } \\
\text { infections or multisystem } \\
\text { diseases in family. }\end{array}$ & $8(7.27 \%)$ \\
\hline $\begin{array}{l}\text { 10. Unusual organism or feature of } \\
\text { systemic immunodeficiency }\end{array}$ & 00 \\
\hline $\begin{array}{l}\text { 11. History suggesting Immuno- } \\
\text { deficiency from first months of } \\
\text { age }\end{array}$ & $13(11.81 \%)$ \\
\hline $\begin{array}{l}\text { 12. Continuous, unremitting or } \\
\text { worsening symptoms }\end{array}$ & 10 (9.09\%) \\
\hline
\end{tabular}

Table 5. Investigations done for the studied group.

\begin{tabular}{|c|c|c|c|}
\hline Item & $\begin{array}{c}\text { 0-3yrs. } \\
\text { "n = 69" }\end{array}$ & $\begin{array}{l}\text { > 3-6yrs. } \\
\text { "n = 15" }\end{array}$ & $\begin{array}{l}\text { > 6yrs. } \\
\text { "n = 26" }\end{array}$ \\
\hline 1-Pulse oximetry“\%” & $94.05 \pm 0.99$ & $92.60 \pm 0.91$ & $96.11 \pm 2.26$ \\
\hline $\begin{array}{l}\text { CBC: } \\
\text { 2-WBCs "Cell/mm3" } \\
\text { 3-Eosinophil "Cell/mm³" } \\
\text { 4-Hb "g/dL" } \\
\text { 5-MCV "FL" } \\
\text { 6-MCH "pg" } \\
\text { 7-Platelets "103/uL" }\end{array}$ & $\begin{array}{c}11.64 \pm 6.42 \\
2.45 \pm 0.39 \\
10.05 \pm 1.55 \\
70.53 \pm 13.35 \\
25.04 \pm 8.84 \\
393.26 \pm 185.56\end{array}$ & $\begin{array}{c}13.04 \pm 3.47 \\
4.83 \pm 0.91 \\
11.42 \pm 1.60 \\
76.44 \pm 3.89 \\
27.09 \pm 4.38 \\
364.40 \pm 78.43\end{array}$ & $\begin{array}{c}13.79 \pm 4.97 \\
3.38 \pm 0.67 \\
11.31 \pm 1.52 \\
70.41 \pm 16.34 \\
25.52 \pm 3.85 \\
308.30 \pm 88.20\end{array}$ \\
\hline 8-CRP “mg/dL" & $36.30 \pm 22.42$ & $38.61 \pm 22.41$ & $42.32 \pm 36.73$ \\
\hline
\end{tabular}


Table 6. Causes of recurrent pneumonia in the studied cases.

\begin{tabular}{lc}
\hline Item & Descriptive “n = 110" \\
\hline 1. Cardiac diseases & $28(25.45 \%)$ \\
2. Immuno-deficiency & $23(20.90 \%)$ \\
3. Bronchial asthma & $18(16.36 \%)$ \\
4. Chronic lung diseases & $15(13.63 \%)$ \\
• Bronchiectasis & $7(6.36 \%)$ \\
• Interstitial lung disease & $8(7.27 \%)$ \\
5. Aspiration syndrome: & $7(6.36 \%)$ \\
- GERD & $4(3.63 \%)$ \\
- Aspiration pneumonia & $3(2.72 \%)$ \\
6. Unknown & $7(6.36 \%)$ \\
7. Tuberculosis & $7(6.36 \%)$ \\
8. Anatomical congenital respiratory & $4(3.63 \%)$ \\
anomalies: & \\
• Tracho-esophgeal fistula & $1(0.90 \%)$ \\
• Vascular ring & $2(1.81 \%)$ \\
• Cleft palate & $1(0.90 \%)$ \\
9. Cystic fibrosis & $1(0.90 \%)$ \\
\hline
\end{tabular}

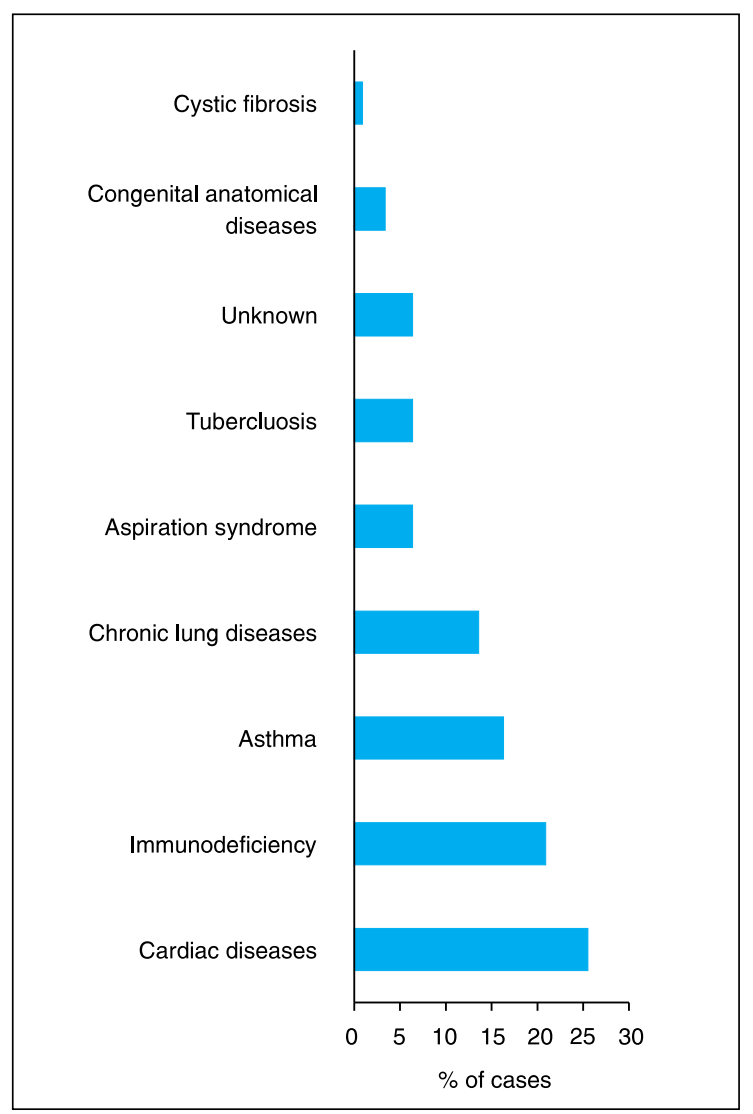

Figure 2. Causes of recurrent pneumonia among the studied patients.

exposed to pollution. Regarding vaccination for T.B and measles it was found that more than $95 \%$ of cases received these vaccines. Father smoking was detected among (36.36\%) of cases.
Table 7. Classification of cardiac causes among patients with recurrent pneumonia.

Item "N=28"

A. Cyanotic heart disease:

1. With decreased pulmonary flow: - Double outlet Rt. Ventricle (with pulmonary stenosis).

2. With increased pulmonary flow:

- Transposition of great arteries. $\quad 5(17.85 \%)$

- Total anomalous pulmonary venous $3(10.71 \%)$

drainage (without pulmonary stenosis).

B-A cyanotic heart diseases:

1. ventricular septal defect.

$8(28.71 \%)$

2. Atrial septal defect

$4(14.28 \%)$

3. Atrio-ventricular septal defect $2(7.14 \%)$

4. Patent ductus arterious. $\quad 5(17.85 \%)$

5. Pink Fallot's tetrology.

$2(7.14 \%)$

Table 8. Classification of causes of immunodeficiency among patients presented with recurrent pneumonia.

\begin{tabular}{ll}
\hline Item & “N = 23” \\
- Phagocytic cell defect”chronic & $6(26.08 \%)$ \\
granulomatous defect disease". & \\
- T-cell deficiency & $2(8.69 \%)$ \\
- B-cell deficiency & $12(52.17 \%)$ \\
- Combined T,B cell deficiency & $3(13.04 \%)$
\end{tabular}

Table 9. Risk factors of recurrent pneumonia in the studied group.

\begin{tabular}{lc}
\hline Item & Descriptive “n = 110" \\
1. Prematurity & $8(7.27 \%)$ \\
2. Feeding history(4. 6months): & \\
Breast feeding & $53(48.18 \%)$ \\
Formula fed & $57(51.81 \%)$ \\
3. Co.morbid conditions: & \\
Heart disease & $30(27.27 \%)$ \\
Oro-motor incoordination/ & $7(6.36 \%)$ \\
swallowing dysfunction & \\
Primary or acquired & \\
immunodeficiency & \\
GERD & \\
Overweight/obesity & $10(9.09 \%)$ \\
4. Smoking (father) & $8(7.27 \%)$ \\
5. Respiratory disease/previous & $7(6.36 \%)$ \\
$\quad$ allergy & $40(36.36 \%)$ \\
6. Vaccinations: & \\
T.B & $31(28.18 \%)$ \\
Influenza & $108(98.2 \%)$ \\
Measles & $10(9.09 \%)$ \\
7. Use steroid & $106(96.36 \%)$ \\
8. Indoor pollution & $9(8.18 \%)$ \\
9. Outdoor pollution & $42(38.18 \%)$ \\
10. undernutrition & $38(34.54 \%)$ \\
& $21(19.09 \%)$ \\
\hline
\end{tabular}

Table 10 shows risk factors in relation to age groups among the studied cases. Patients aged $>6$ years showed significantly higher frequency in risk factors as obesity, indoor and outdoor pollution and use of 
Table 10. Risk factors of recurrent pneumonia in relation to age groups among the studied cases.

\begin{tabular}{|c|c|c|c|c|}
\hline Item & $\begin{array}{l}\text { 0-3yrs. } \\
\text { "n = 69" }\end{array}$ & $\begin{array}{l}>3-6 y r s . \\
\text { "n = 15" }\end{array}$ & $\begin{array}{l}\text { > 6yrs. } \\
\text { "n = 26" }\end{array}$ & P-value \\
\hline $\begin{array}{l}\text { 1. Prematurity } \\
\text { 2. Feeding history(4.6months): }\end{array}$ & $12(17.39 \%)$ & $3(20.0 \%)$ & $2(7.69 \%)$ & $P=0.442 n . s$ \\
\hline Breast feeding & $35(50.72 \%)$ & $6(40.0 \%)$ & 12 (46.15\%) & $P=0.732 n . s$ \\
\hline Formula fed & $34(49.27 \%)$ & $9(60.0 \%)$ & $14(53.84 \%)$ & \\
\hline 3. Co-morbid: & & & & $P<0.006$ \\
\hline Heart disease & $26(37.68 \%)$ & $1(6.66 \%)$ & $3(11.53 \%)$ & $P=0.108 n . s$ \\
\hline $\begin{array}{l}\text { Oro-motor incoordination/swallowing } \\
\text { dysfunction }\end{array}$ & 7 (10.14\%) & 0 & 0 & \\
\hline $\begin{array}{l}\text { Primaryor acquired immunodeficiency } \\
\text { GERD }\end{array}$ & 9 (13.04\%) & $8(53.33 \%)$ & $6(23.07 \%)$ & $P=0.135 n . s$ \\
\hline Overweight/obesity & $4(3.63 \%)$ & 0 & 0 & $P=0.077 n . s$ \\
\hline 4. Smoking in parents: & 0 & $1(6.66 \%)$ & $6(23.07 \%)$ & $P<0.000$ \\
\hline 5. Respiratordisease/previous allergy & $16(23.9 \%)$ & $7(46.7 \%)$ & $17(65.4 \%)$ & $P<0.001$ \\
\hline 6. Vaccinations: & $22(31.88 \%)$ & $5(33.3 \%)$ & $4(15.38 \%)$ & $P<0.001$ \\
\hline T.B & $68(98.6 \%)$ & $(100 \%)$ & $5(96.2 \%)$ & $P=0.628 n . s$ \\
\hline Influenza & 0 & $3(20 \%)$ & 7 (26.9\%) & $P<0.03$ \\
\hline Measles & 67 (97.9\%) & 15 (100\%) & 26 (95.7\%) & $P=0.493 n . s$ \\
\hline 8. Use steroid & $2(2.9 \%)$ & 0 & 7 (26.9\%) & $P<0.01$ \\
\hline 9. Indoor pollution & $23(33.33 \%)$ & $5(33.33 \%)$ & 14 (53.84\%) & $P<0.01$ \\
\hline 10. Outdoor pollution & $19(27.53 \%)$ & $4(26.67 \%)$ & 15 (57.69\%) & $P<0.04$ \\
\hline 11. undernutrition & $16(23.18 \%)$ & $3(20.0 \%)$ & $2(7.69 \%)$ & $P<0.001$ \\
\hline
\end{tabular}

steroids in comparison to other age groups. However, patients aged 0-3 years exhibited significantly higher \% frequency of having heart disease, oro-motor incoordination/swallowing dysfunction, GERD and undernutrition as risk factors for recurrent pneumonia in comparison to other age groups.

\section{Discussion}

In present study, pneumonia was diagnosed in 872 of admitted cases and 110 cases fulfilled the inclusion criteria of recurrent pneumonia $12.61 \%$. This agrees with Saad and his colleges (2013)(11) who found in previous study in Assiut in Upper Egypt that $9.2 \%$ of patients with pneumonia met the definition of recurrent/persistent pneumonia, $7 \%$ for recurrent and $2.2 \%$ for persistent pneumonia .Also Morcos and his colleges (2016)(12) reported that $12 \%$ had recurrent pneumonia in El Galaa Teaching Hospital in Egypt. Similarly; $1-9 \%$ of patients met the criteria for recurrent pneumonia in previous studies $(13,14)$. However, other studies, Bolursaz et al (2017) (15) reported prevalence of $34.64 \%$ of RP among patients with pneumonia in Tahran, Iran.

In present study, $65.5 \%$ of cases were males. This agrees with previous study done in Assiut University Hospital by Saad et al (2013)(11) as male patients represent $65 \%$ and female represents $35 \%$ of included RP cases. Bolursaz et al (2017)(15) also found that $55.0 \%$ of cases were males in Iran, that can be explained as male patients are more vulnerable to infections than female, also the tradition of favoring male to female in the community makes parents seek medical advice for male children earlier and more frequent. The majority of the included patients were belonged to age group $0-3$ years $(62.7 \%)$. This agrees with Bolursaz et al (2017) (15) who reported that $1 \%$ had onset of symptoms before 3 months of age, $6 \%$ between 3 and 12 months, $65 \%$ between 1 and 5years and $28 \%$ after the age of $5 y e a r s$, that can be explained as the age group 0-3 years had significantly higher \% frequency of presence of co morbid conditions as congenital anomalies, congenital heart disease and under nutrition. $77.27 \%$ of included cases were from urban areas, while $22.72 \%$ of included RP cases were from rural areas. This agrees with $\mathrm{Li}$ and his colleges (2017) (16) who reported that incidence of childhood pneumonia generally higher in urban areas with percentage of $73.45 \%$ for urban residents versus $26.55 \%$ for rural areas.

In the present study, there was history of cough among $94.45 \%$ of the patients, and $56.36 \%$ had history of fever while $50.0 \%$ had history of recurrent upper respiratory tract infection .Less than third of cases $22.72 \%$ had history of atopy/allergy and about $11.81 \%$ of cases had history of immuno-deficiency from first months of age. This agrees with Çapanoglu et al (2017) (17) who reported the most common presenting symptom was cough $95.5 \%$, followed by fever $59.9 \%$ and wheezing $47.9 \%$.

Our results are in line with Çapanoglu et al (2017) (17) who reported congenital heart diseases were the 
most important cause for recurrent pneumonia in 33.9\% of children with RP. Dilated blood vessels or chambers of the heart may compress the bronchi, causing impaired drainage of pulmonary segments. Also patients with congenital lesions causing left-to-right shunting and an increased pulmonary blood flow have an increased susceptibility to respiratory infections. Previous studies have reported congenital heart disease in 1.2-25.4\% of cases $(10,13,14)$. A left-to-right shunt can adversely affect lung function, and superimposed lower respiratory tract infections cause additional compromise and might lead to respiratory failure (18). In agreement with these figures, our results demonstrated that congenital heart diseases was identified among $25.45 \%$ of cases and TGA was diagnosed in $17.85 \%$ of the cardiac cases, while $28.7 \%$ of cardiac patients with a cyanotic heart diseases had ventricular septal defect.

In present study, $6.36 \%$ of studied cases were due to aspiration syndrome, $3.36 \%$ with GERD and $2.72 \%$ with aspiration pneumonia (in spite of patients with obvious neurological diseases that lead to recurrent pneumonia were excluded from our study). Gastro-esophageal reflux disease was diagnosed in four children by clinical suspicion and confirmed by barium swallow. This agrees with Owayed et al (2000) (10) who reported that in developed countries, aspiration is considered an important cause of RP and could be due to gastro-esophageal reflux disease (GERD) or due to pharyngeal in coordination. Reflux should be confirmed by esophageal $\mathrm{P}^{\mathrm{Hh}}$ study, while video fluoroscopy should be used to confirm in coordination. Technetium scan, esophagoscopy and biopsy may be used if $\mathrm{P}^{\mathrm{Hh}}$ study is not conclusive, although in many cases the history would be sufficient (19).

In present study, $20.9 \%$ of studied cases proved to have immune-deficiency diseases. $52.17 \%$ of them were due to $B$-cell defect, $26.08 \%$ with chronic granulomtous disease, $13.04 \%$ due to combined $T$ and $B$ cell deficiency and $8.69 \%$ due to T cell defect. This agrees with Patria \& Esposito (2013) and Hoving \& Brand $(2013)(2,18)$ who reported that immune deficiency disorders were present among $7.7-17.75 \%$ of cases of RP. Children with immune defects usually present with highly recurrent and/or severe bacterial infections of the respiratory tract without any seasonality, recurrent gastrointestinal infections and recurrent skin infections. The family history of immunodeficiency is often characterized by recurrent infections and early deaths. There is often a delay of years between the onset of symptoms and the diagnosis being made: this delay increases the risk of bronchiectasis and irreversible lung damage occurring before appropriate treatment is given (20).

In present study, cases with RP have asthma represented $16.36 \%$ of studied cases. This agrees with Douglas \& Couriel (2001) (21) who reported asthma was diagnosed among $9.7 \%$ of studied patients. Asthma is the most important underlying illness for recurrent pneumonia in children reported by different researchers accounting for $15 \%-69 \%$ of cases $(14,22,23)$. The notion that asthma in children can be complicated by recurrent pneumonia has a long history and contributes to the confusion when assessing these children. This is especially true when the RML is involved. The right middle lobe syndrome is subject to atelectasis because of the anatomy of the bronchus and the lack of collateral ventilation with other lobes. Excess mucus production in hypersecretory asthma can lead to RML atelectasis. It is well recognized that the most common cause of the so-called 'right middle lobe syndrome' is asthma (24). Atopy was considered as an important risk factor for RP due to defective innate immune response of epithelial cells and interleukin 13-dependant reduced mucociliary clearance $(25,26)$. Allergic inflammation may also suppress the interferon response of innate immunity under certain circumstances (27). In contrast to our study and previous studies, Hoving \& Brand (2013) (2) reported that asthma was not diagnosed as an underlying cause of recurrent pneumonia in their study. They believed that asthma is a rare cause of recurrent pneumonia in children, and if occurs this seems to be confined to very unusual and complicated cases of asthma.

Tuberculosis is one of the most common infectious diseases among children in the world. TB is suspected when an ill child has a history of chronic illness of usually more than 3 weeks of duration that includes cough and fever, weight loss or failure to thrive (28). Tuberculosis is a common cause of extra luminal compression of the airways associated with recurrent lung infections (18). In the present study, $6.36 \%$ of cases RP was due to tuberculosis. This agrees with Lodha et al (2002) (29) who reported pulmonary TB as a cause of recurrent pneumonia in $7.1 \%$ of patients. In addition, Çelebi (2010) and his colleagues (30) reported TB in $4.8 \%$ of the cases. The relatively low percentage frequency of TB as a cause for RP in our study may be suggested by the high rate of vaccination $98.6 \%$ among our studied cases. In previous studies with recurrent pneumonia, $(13,22)$ reported pulmonary TB as a cause in $19.2 \%$ and $31.5 \%$ of patients, respectively. This relatively high prevalence of pulmonary TB should alarm the physicians and health authorities to take more intensive measures for prevention and control of this disease in these areas.

The present study demonstrated that, $13.63 \%$ of studied cases have chronic lung diseases, $7.27 \%$ with interstitial lung disease while bronchiectasis represented $6.36 \%$ of included cases. These results matching with recent hypothesis that RP early in life is a major risk factor for bronchiectasis (31), but only some children actually develop bronchiectasis after the first episodes of pneumonia. The early identification of 
the patients at the highest risk of bronchiectasis could allow a diagnosis to be made when the bronchial wall lesions are still mild, thus favoring the implementation of appropriate preventive and therapeutic measures, and a better final prognosis (32). The development of bronchiectasis is a chronic, progressive pulmonary disorder characterized by the permanent dilatation of one or more bronchi due to structural modifications in the bronchial wall (33). In pediatric patients, bronchiectasis causes an accelerated decline in lung function that leads to repeated hospital admissions due to acute infectious exacerbations, a poorer quality of life, and possible premature death in early adult life (34). Recurrent pneumonia was considered as a risk factor for development of bronchiectasis in $6.7 \%-8.5 \%$ of cases $(1,10)$.

In the present study, 4 patients $3.63 \%$ had congenital anatomical anomalies of the respiratory tract one patient had tracho-esophageal fistula, 2 had congenital vascular ring and one had cleft palate. Previous studies have reported congenital anomalies of the respiratory tract in $3.7-8.5 \%$ of cases $(2,10,29)$. Recurrent chest infections are often the presenting feature of congenital abnormalities of the airways, lung parenchyma and pulmonary vasculature. For example, repeated episodes pneumonia are often the presenting feature of lobar sequestration, bronchial stenosis and bronchomalacia,and cystic adenomatoid malformations of the lung (35). Such an abnormality should be suspected if one lobe is repeatedly infected or if there is there is incomplete resolution after treatment. Computerized tomography and magnetic resonance scanning are helpful in defining the anomaly prior to surgical excision (36).

In our study the etiology of recurrent pneumonia was not recognized in $6.36 \%$ of studied cases in spite of careful history obtained and full investigation done to these cases. This agrees with Çapanoglu et al (2017) (17) who mentioned that the underlying cause of recurrent pneumonia was no specific in $16.3 \%$ of studied cases and Saad and his colleges (2013) (11) who mentioned also that in $10-20 \%$ of studied cases the etiology was unknown.

The current study showed that only one case had cystic fibrosis, diagnosed by cystic fibrosis DNA analysis .Limited data are available regarding CF prevalence among Egyptian children's has been believed to occur infrequently in Egypt; only few papers suggested its presence $(37,38)$.A history of neonatal jaundice, poor weight gain, steatorrhea and highly recurrent pneumonia may suggest cystic fibrosis, although atypical cases may present with recurrent pneumonia alone, in the absence of malabsorption. Also recovery of pseudomonas aeruginosa from the respiratory tract, especially the mucoid form, is highly suggestive of CF $(18,39)$.

In present study, according to El Sherbini modified score (2012) $48.18 \%$ of the families belonged to middle class, while $43.63 \%$ were classified as low class. This agrees with Wonodi et al (2012); Çapanoglu et al (2017) $(17,40)$ who reported risk factors associating with RP in children especially poor socioeconomic status which represent an important risk factor commonly associated with increase the frequency of illness episodes in children .

Also high crowding index according to El Sherbini modified score (2012) was detected among 94.5\% which represent important risk factor for recurrent pneumonia mostly due to increased exposure to respiratory pathogens (41). The definition of household crowding varies greatly (42). Household crowding was defined as two or more individuals sleeping in the same room as the child (43) or more 7 persons per household (44). Our results match with Çapanoglu et al (2017) (17) who reported overcrowded household as a definitive risk factor of RP.

In our study, we also found that $54.4 \%$ of mothers of studied cases only read and write and $29.29 \%$ of them had preparatory level of education. This agrees with De Souza et al (2000) (45) who mentioned that mother's education level has an undeniable and important impact on their children's health and understanding of them of the importance of the disease, its severity and use of health services. Also Nirmolia et al (2018) (46) showed lack of maternal education is significantly associated with occurrence of pneumonia.

History of prematurity was detected among $7.27 \%$ of studied cases. This agrees with Çapanoglu and his colleges (2017) (17) who mentioned prematurity as an important risk factor for pneumonia recurrence in children. The two main mechanisms that children with low birth weight put at risk of respiratory infections include low immunity level and defects in lung function. Also, these children also have limited iron, zinc and copper resources (47).Other studies that have been conducted in developing countries, showed the relationship between birth weight and infant mortality due to pneumonia or acute infection of the lower respiratory tract (48).Yoon et al (1997) (49) mentioned that a strong correlation exists between decreased mortality from pneumonia with increasing birth weight.

In the present study, $36.36 \%$ of studied cases had history of parental smoking which becomes one of the important risk factors for RP. This agrees with Çapanoglu et al (2017) (17) who reported that exposure to smoking presented in $57.1 \%$ of studied cases with RP. Passive smoking is a risk factor for developing respiratory tract infections in children (50). Passive smoking in children leads to suppression of phagocytic function and cilia cell activity, increase the likelihood of adherence of bacteria to the epithelium of respiratory tract (51).

According to our study, $19.09 \%$ of studied cases have under malnutrition. This agrees with most of 
studies done before in the developing countries which reported strong correlation between under malnutrition and pediatric recurrent infections especially respiratory tract infections (51).Children with malnutrition have deficient immune responses, consequently these childhood infections are more severe in these children. Studies show children who their weight is less than $70 \%$ appropriate weight for their age compared to other children, increased an 8 times risk of mortality from pneumonia for them (48).

In present study $51.8 \%$ of studied cases were formula fed and only $48.2 \%$ were exclusive breast fed . This agrees with Çapanoglu et al (2017) (17) who mentioned that insufficient breastfeeding was one of the definitive risk factors strongly associated with increasing the frequency of RP. Ulshen (2005) (52) reported that breastfeeding can protect children against the risk of lower respiratory infections. In fact, breast milk gives passive protection against pathogens even with change of age infants (53).Complete or partial breast-feeding resulted in a $50 \%$ reduction in mortality from acute respiratory tract infections in children fewer than 18 months (54).

In present study $38.18 \%$ of cases with recurrent pneumonia exposed to indoor air pollution .There are documentations that the risk of pneumonia is enhanced following exposure to unprocessed solid fuel use by a factor of 1.8 (55) and also there is significant association between ARI and indoor air pollution (56). Nirmolia et al (2018) (46) have documented a significant association between indoor air pollution and pneumonia. It has been recommended that prevention of indoor air pollution from burning of solid fuel to switching over to better quality fuel, improved ventilation or some other measures will substantially reduce morbidity and mortality from pneumonia (55).This agrees with Po, et al (2011) ; Searing and Rabinovitch $(2011)(57,58)$ who reported that both indoor and outdoor pollution are a definitive risk factors for RP. Dherani et al (2008) (55) also reported that indoor air pollution has been determined to elevate the risk of pneumonia in children by approximately $80 \%$.

\section{Conclusion}

1-Approximately 1 in 12 children with pneumonia in our locality have recurrent pneumonia with percentage of $12.61 \%$. The most frequent underlying cause for recurrent pneumonia in Assiut University Children's Hospital which present the largest referral pediatric hospital in Upper Egypt for one year according to our study was cardiac diseases especially congenital heart diseases $25.45 \%$, the second most frequent cause was immunodeficiency diseases $20.9 \%$ followed by bronchial asthma $16.36 \%$. Other causes include chronic lung diseases, pulmonary T.B, aspiration syndrome, anatomical congenital respiratory anomalies and cystic fibrosis arranged respectively, while the etiology of recurrence was unknown in $6.36 \%$ of the cases.

2-Prematurity was detected among $7.27 \%$ of the cases while more than $50 \%$ were formula fed and more than $60 \%$ exposed to pollution. Father smoking was detected among $36.36 \%$ of cases. Patients aged $>6$ years showed significantly higher frequency in risk factors as obesity, indoor and outdoor pollution and use of steroids in comparison to other age groups. However, patients aged $0-3$ years exhibited significantly higher $\%$ frequency of having heart disease, oro-motor in coordination /swallowing dysfunction, GERD and under nutrition as risk factors for recurrent pneumonia in comparison to other age groups.

Finally, we hope that this study will help the pediatricians identify and hence prevent and manage the most common etiologies of recurrent pneumonia in our locality. Determining which case should be investigated relies on clinical judgment, depending on a careful history and physical examination, whether the child is improving clinically and whether there is any feature suggestive of an underlying condition. Early treatment of the child's underlying condition is crucial in order to stabilize lung disease and thus prevent progressive deterioration of most pulmonary diseases.

A wide range of tests is available and there is no evidence base to guide the clinician on the most appropriate timing or sequence of investigations. Ideally, the diagnosis should be confirmed or excluded with the minimum number of the least-invasive tests. The economic burden of an extensive diagnostic work-up should always be kept in mind. Choosing the most appropriate investigations for recurrent pneumonia should be individualized for every case separately according to detailed history and full clinical examination for each case.

\section{References:}

1. Weigl JAI, Bader HM, Everding A, et al. Population-based burden of pneumonia before school entry in Schleswig-Holstein, Germany. Eur J Pediatr. 2003; 162(5): 309-316, doi: 10.1007/s00431-002-1140-4, indexed in Pubmed: 12692711.

2. Hoving MF, Brand PLP. Causes of recurrent pneumonia in children in a general hospital. J Paediatr Child Health. 2013; 49(3): E208-E212, doi: 10.1111/jpc.12114, indexed in Pubmed: 23438187.

3. WHO/UNICEF (2009). Global action plan for prevention and control of pneumonia (GAPP). Geneva: World Health Organization.

4. $\mathrm{WHO}(2014)$. Revised $\mathrm{WHO}$ classification and treatment of childhood pneumonia at health facilitiese Evidence summaries. Geneva:World Health Organization

5. WHO/UNICEF (2013). Ending preventable child death from pneumonia and diarrhea by2025: The integrated action plan for pneumonia and diarrhea (GAPPD). Geneva:World Health Organization.

6. UNICEF, WHO(2006). Pneumonia. The forgotten killer of children. New York: UN Children's Fund:Geneva: World Health Organization.

7. Schnabel E, Sausenthaler S, Brockow I, et al. LISA Study Group. Burden of otitis media and pneumonia in children up to 6 years of 
age: results of the LISA birth cohort. Eur J Pediatr. 2009; 168(10): 1251-1257, doi: 10.1007/s00431-008-0921-9, indexed in Pubmed: 19159954.

8. -Wald E. Recurrent and non-resolving pneumonia in children. SeminRespir Infect. 1993; 8: 46-58.

9. Montella S, Corcione A, Santamaria F. Recurrent Pneumonia in Children: A Reasoned Diagnostic Approach and a Single Centre Experience. Int J Mol Sci. 2017; 18(2), doi: 10.3390/ijms18020296, indexed in Pubmed: 28146079

10. Owayed AF, Campbell DM, Wang EE. Underlying causes of recurrent pneumonia in children. Arch Pediatr Adolesc Med. 2000; 154(2): 190-194, indexed in Pubmed: 10665608

11. Saad K, Mohamed SA, Metwalley KA. Recurrent/Persistent Pneumonia among Children in Upper Egypt. Mediterr J Hematol Infect Dis. 2013; 5(1): e2013028, doi: 10.4084/MJHID.2013.028, indexed in Pubmed: 23667726.

12. -Morcos MW, Azmy A, Abu sh, et al. El Galaa Teaching Hospital, Egypt, Der pharma Chemica. 2016; 8(23): 16-21.

13. Kumar M, Biswal N, Bhuvaneswari V, et al. Persistent pneumonia: Underlying cause and outcome. Indian J Pediatr. 2009; 76(12): 1223-1226, doi: 10.1007/s12098-009-0272-1, indexed in Pubmed: 19941090

14. - Ozdemir O, Sari S, Bakirtas A. Zorlu P, Ertan U. Underlying diseases of recurrent pneumonia in Turkish children. Turk J Med Sci. 2010 40(1): 25-30

15. Bolursaz MR, Lotfian F, Ghaffaripour HA, et al. Underlying Causes of Persistent and Recurrent Pneumonia in Children at a Pulmonary Referral Hospital in Tehran, Iran. Arch Iran Med. 2017; 20(5): 266-269, doi: 0172005/AIM.003, indexed in Pubmed: 28510461.

16. - Li Y, An Z, Yin D, et al. HUMAN VACCINES \& IMMUNO-THERAPEUTICS : VOL. 13. 2017; 7: 1681-1687.

17. ÇAPANOĞLU M, ZORLU P, SARI E, et al. The Etiology of Recurrent Pneumonia with Onset During Infancy, and the Effect of Risk Factors on Age at First Episode and Episode Frequency. Turkish Journal of Pediatric Disease. 2017, doi: 10.12956/tjpd.2017.274

18. Patria MF, Esposito S. Recurrent lower respiratory tract infections in children: a practical approach to diagnosis. Paediatr Respir Rev. 2013; 14(1): 53-60, doi: 10.1016/j.prrv.2011.11.001, indexed in Pubmed: 23347661.

19. Yousif TI, Elnazir B. Approach to a child with recurrent pneumonia. Sudan J Paediatr. 2015; 15(2): 71-77, indexed in Pubmed: 27493439.

20. Brand PLP, Hoving MF, de Groot EP. Evaluating the child with recurrent lower respiratory tract infections. Paediatr Respir Rev. 2012; 13(3) 135-138, doi: 10.1016/j.prrv.2011.02.005, indexed in Pubmed: 22726867.

21. -Douglas T, Couriel J. Differential diagnosis of asthma in children Asthma J. 2001: 6: 72-76.

22. Lodha R, Puranik $M$, Chandra $U$, et al. Persistent pneumonia in children. Indian Pediatr. 2003; 40(10): 967-970, indexed in Pubmed: 14581735.

23. Ciftçi $E$, Güneş $M$, Köksal $Y$, et al. Underlying causes of recurrent pneumonia in Turkish children in a university hospital. J Trop Pediatr. 2003; 49(4): 212-215, doi: 10.1093/tropej/49.4.212, indexed in Pubmed: 12929881.

24. Hughes D. Recurrent pneumonia ... Not! Paediatrics \& Child Health 2013; 18(9): 459-460, doi: 10.1093/pch/18.9.459.

25. Hellings PW, Fokkens WJ. Allergic rhinitis and its impact on otorhinolaryngology. Allergy. 2006; 61(6): 656-664, doi: 10.1111/j.1398-9995.2006.01109.x, indexed in Pubmed: 16677233.

26. O'Reilly MA, Marr SH, Yee M, et al. Neonatal hyperoxia enhances the inflammatory response in adult mice infected with influenza A virus. Am J Respir Crit Care Med. 2008; 177(10): 1103-1110, doi: 10.1164/rccm.200712-18390C, indexed in Pubmed: 18292469

27. Tversky JR, Le TV, Bieneman AP, et al. Human blood dendritic cells from allergic subjects have impaired capacity to produce interferon-alpha via Toll-like receptor 9. Clin Exp Allergy. 2008; 38(5) 781-788, doi: 10.1111/j.1365-2222.2008.02954.x, indexed in Pubmed: 18318750 .

28. Singh V. TB in developing countries: diagnosis and treatment Paediatr Respir Rev. 2006; 7 Suppl 1: S132-S135, doi: 10.1016/j. prrv.2006.04.222, indexed in Pubmed: 16798539

29. Lodha R, Puranik M, Natchu UCM, et al. Recurrent pneumonia in children: clinical profile and underlying causes. Acta Paediatr. 2002; 91(11): 1170-1173, indexed in Pubmed: 12463313

30. Celebi S, Hacimustafaoglu M, Albayrak Y, et al. Recurrent Pneumonia in Children. Çocuk Enfeksiyon Dergisi/Journal of Pediatric Infection. 2010; 4(2): 56-59, doi: 10.5152/ced.2010.02.
31. Chang AB, Byrnes CA, Everard ML. Diagnosing and preventing chronic suppurative lung disease (CSLD) and bronchiectasis. Paediatr Respir Rev. 2011; 12(2): 97-103, doi: 10.1016/j.prrv.2010.10.008, indexed in Pubmed: 21458737

32. Patria MF, Longhi $B$, Lelii $M$, et al. Children with recurrent pneumonia and non-cystic fibrosis bronchiectasis. Ital J Pediatr. 2016; 42: 13, doi: 10.1186/s13052-016-0225-z, indexed in Pubmed: 26861259

33. King P. Pathogenesis of bronchiectasis. Paediatr Respir Rev. 2011 12(2): 104-110, doi: 10.1016/j.prrv.2010.10.011, indexed in Pubmed 21458738.

34. Gokdemir Y, Hamzah A, Erdem E, et al. Quality of life in children with non-cystic-fibrosis bronchiectasis. Respiration. 2014; 88(1): 46-51, doi: 10.1159/000360297, indexed in Pubmed: 24820893

35. -Cabezuelo $\mathrm{H}$, Vidal $\mathrm{M}$, Abeledo $\mathrm{G}$, et al. Underlying causes of recurrent pneumonia. An Pediatr (Barc. 2005; 63: 409-412.

36. Panitch HB. Evaluation of recurrent pneumonia. Pediatr Infect Dis J. 2005; 24(3): 265-266, indexed in Pubmed: 15750465.

37. AbS, Samuel S, Awad M, et al. Abdel- Meguid IE, Azmy J. Cystic fibrosis in Egyptian children: neonatal screening and high risk groups. JAC 1993; 4: 313-317.

38. Naguib ML, Schrijver I, Gardner P, et al. Cystic fibrosis detection in high-risk Egyptian children and CFTR mutation analysis. J Cyst Fibros. 2007; 6(2): 111-116, doi: 10.1016/j.jcf.2006.04.004, indexed in Pubmed: 16837250

39. Couriel J. Assessment of the child with recurrent chest infections Br Med Bull. 2002; 61: 115-132, indexed in Pubmed: 11997302.

40. Wonodi CB, Deloria-Knoll M, Feikin DR, et al. Pneumonia Methods Working Group and PERCH Site Investigators. Evaluation of risk factors for severe pneumonia in children: the Pneumonia Etiology Research for Child Health study. Clin Infect Dis. 2012; 54 Suppl 2: S124-S131, doi: 10.1093/cid/cir1067, indexed in Pubmed: 22403226

41. Cardoso MR, Cousens SN, de Góes Siqueira LF, et al. Crowding: risk factor or protective factor for lower respiratory disease in young children? BMC Public Health. 2004; 4: 19, doi: 10.1186/1471-2458-4-19, indexed in Pubmed: 15176983

42 Jackson $\mathrm{S}$, Mathews $\mathrm{KH}$, Pulanic $\mathrm{D}$ et al. Risk factors for severe acute lower respiratory infections in children: a systematic review and meta-analysis. Croat Med J. 2013; 54(2): 110-121, indexed in Pubmed: 23630139

43. Fonseca Lima EJ, Mello MJ, Albuquerque Md, et al. Risk factors for community-acquired pneumonia in children under five years of age in the post-pneumococcal conjugate vaccine era in Brazil: a case control study. BMC Pediatr. 2016; 16(1): 157, doi: 10.1186/s12887-016-0695-6, indexed in Pubmed: 27659204

44. Rudan I, Boschi-Pinto C, Biloglav Z, et al. Epidemiology and etiology of childhood pneumonia. Bull World Health Organ. 2008; 86(5): 408-416, indexed in Pubmed: 18545744

45. Terra de Souza AC, Peterson KE, Andrade FM, et al. Circumstances of post-neonatal deaths in Ceara, Northeast Brazil: mothers' health care-seeking behaviors during their infants' fatal illness. Soc Sci Med. 2000; 51(11): 1675-1693, indexed in Pubmed: 11072887.

46. Nirmolia N, Mahanta T, Boruah M, et al. Prevalence and risk factors of pneumonia in under five children living in slums of Dibrugarh town. Clinical Epidemiology and Global Health. 2018; 6(1): 1-4, doi: 10.1016/j.cegh.2017.07.004

47. Huong PL, Hien PT, Lan NT, et al. First report on prevalence and risk factors of severe atypical pneumonia in Vietnamese children aged 1-15 years. BMC Public Health. 2014; 14: 1304, doi: 10.1186/14712458-14-1304, indexed in Pubmed: 25524126.

48. Lehmann D, Howard P, Heywood P, et al. Nutrition and morbidity: acute lower respiratory tract infections, diarrhoea and malaria. P N G Med J. 1988; 31(2): 109-116, indexed in Pubmed: 3140508.

49. Yoon PW, Black RE, Moulton LH, et al. The effect of malnutrition on the risk of diarrheal and respiratory mortality in children $<2$ y of age in Cebu, Philippines. Am J Clin Nutr. 1997; 65(4): 1070-1077, doi: 10.1093/ajcn/65.4.1070, indexed in Pubmed: 9094895

50. Peat JK, Keena V, Harakeh Z, et al. Parental smoking and respiratory tract infections in children. Paediatr Respir Rev. 2001; 2(3): 207-213, doi: 10.1053/prrv.2001.0142, indexed in Pubmed: 12052321.

51. -Ramezani M, Aemmi SZ, Moghadam ZE. Factors Affecting the Rate of Pediatric Pneumonia in Developing Countries: a Review and Literature Study. Int J Pediatr; Vol.3, N. 6-2, Serial No. 2015; 24.

52. Ulshen M. Pediatric gastrointestinal disease. Gastroenterology. 2005; 128(5): 1526-1527, doi: 10.1053/j.gastro.2005.03.064

53. Effect of breastfeeding on infant and child mortality due to infectious diseases in less developed countries: a pooled analysis. WHO Colla- 
borative Study Team on the Role of Breastfeeding on the Prevention of Infant Mortality. Lancet. 2000; 355(9202): 451-455, indexed in Pubmed: 10841125.

54. Victora C. Infection and Disease: The Impact of Early Weaning. Food and Nutrition Bulletin. 2018; 17(4): 1-8, doi: 10.1177/156482659601700421.

55. Dherani M, Pope D, Mascarenhas M, et al. Indoor air pollution from unprocessed solid fuel use and pneumonia risk in children aged under five years: a systematic review and meta-analysis. Bull World Health Organ. 2008; 86(5): 390-398C, indexed in Pubmed 18545742
56. Taksande A, Yeole M. Risk factors of acute respiratory infection (ARI) in under- fives in a rural hospital of Central India. J Pediatric Neonatal Individual Med. 2016; 5(1): e050105.

57. Po JYT, FitzGerald JM, Carlsten C. Respiratory disease associated with solid biomass fuel exposure in rural women and children: systematic review and meta-analysis. Thorax. 2011; 66(3): 232-239, doi: 10.1136/thx.2010.147884, indexed in Pubmed: 21248322.

58. Searing D, Rabinovitch N. Environmental pollution and lung effects in children. Current Opinion in Pediatrics. 2011; 23(3): 314-318, doi: 10.1097/mop.0b013e3283461926. 